\title{
TAKING AN ETHICS OF CARE PERSPECTIVE ON TWO UNIVERSITY TEACHER TRAINING PROGRAMMES
}

\author{
S. Bennoun* \\ e-mail: steve.bennoun@gmail.com \\ P. Haeberli* \\ e-mail: philippe.haeberli@unige.ch
}

\section{Schaub*}

e-mail: mallory.schaub@unige.ch

*Pôle SEA (DIFE)

University of Geneva

Switzerland

\section{ABSTRACT}

This article shows the usefulness and interest of taking an ethics of care perspective to evaluate university teacher training programmes. More precisely, in this case study we use the five elements of care identified by Tronto - attentiveness, responsibility, competence, responsiveness and trust - to assess two multiple-day training programmes offered at the University of Geneva. We show how small changes in our practice such as giving some choice to the participants over the topics addressed, adapting the schedule to meet the participants' constraints or dedicating time slots specifically for the questions and concerns raised by the participants can have a big impact on the level of care provided. We moreover argue that this framework brings interesting and novel elements that appropriately "counterbalances" traditional evaluations that are usually implicitly based on notions such as performance, efficiency and measurability. Finally, we briefly explain how the ethics of care could be used a basis to not only evaluate but to rethink and elaborate training programmes.

Keywords: faculty development, ethics of care, university teaching, teacher training

\section{INTRODUCTION}

As it is common in many universities around the world, the University of Geneva offers teacher training programmes to its teaching staff. For a few years, the Teaching and Learning Support Centre (Pôle SEA) has in particular been organising two relatively equivalent multiple-day training programmes, one in French and the other in English. These programmes, as well as the other workshops organised by the Centre, are routinely evaluated through online surveys sent to the participants. While this brings interesting information, this procedure also presents 
limitations, for example, because most items are evaluated on a 4-point scale. Moreover, these surveys implicitly use notions currently dominant such as efficiency, expertise, measurability or performance.

In this article, we take a different perspective and use Tronto's political ethics of care framework $(1993 ; 2013)$ to assess our two multiple-day training programmes. The interest of such an approach comes from the fact that much has been written about the implementation of such training programmes but not much literature exists the use of normative frameworks to evaluate them (Bozalek et al. 2014). Moreover, the case study presented in this article shows how using this framework provides interesting and novel information about teacher training programmes. Indeed, by focusing on the five elements of care - attentiveness, responsibility, competence, responsiveness and trust - identified by Tronto $(1993,2013)$, we are able to point out aspects of our training programmes that would otherwise go unnoticed. This new perspective also enables us to explain and underline the importance of those practices that would otherwise seem minor and unimportant. Finally, this comparison and analysis of our practices gives us the possibility to identify needs of our participants that may not be met in our current practices. In that sense, the use of the ethics of care framework with its emphasis on people's needs gives an interesting "counterbalance" to dominant values of our time such as efficiency, knowledge, expertise or performance (that are often described as "neoliberal").

We will first provide a background to the study by describing the two training programmes under consideration. We then provide a methodology and thereafter use the five elements of care to analyse these two workshops. We finally conclude by discussing the interest of using such a framework to evaluate university teacher training programmes.

\section{BACKGROUND}

For over 3 years the Teaching and Learning Support Centre at the University of Geneva has been offering two multiple-day workshops giving a global overview of university teaching. The goal of these workshops is to introduce participants to important concepts in university teaching and to address major aspects of teaching in a higher education institution. We describe here the two workshops as well as their similarities and differences.

The first workshop is called FormA and is given in French. It was developed at the University of Geneva and its earlier version started in 2003 (the first version that corresponds to the current one was given for the first time in 2006). The workshop is composed of three independent modules of two and half days. Each module focuses on a specific topic: communication, teaching, and assessment. They can be followed in any order. All the modules are taught in an active learning way. During the module on communication, the participants 
give two 5-minute presentations and receive feedback on it from their peers and from the facilitator. Each module can be validated through a validation work. This work is done with the help and supervision of a faculty developer of the teaching centre. Possible ways to validate a module include: for the module on communication: the participant prepares and gives a presentation (or a lecture) and then receives oral and video feedback from the faculty developer; for the module on teaching: the participant prepares a lesson plan, delivers the lesson and receives feedback from the faculty developer on it; for the module on assessment, the participant builds a rubric for his or her course. When the three modules are validated the participants can attend a half-day integration seminar where the different problematics seen in the modules are discussed and put into perspective.

In terms of audience, this training is mainly followed by $\mathrm{PhD}$-student teaching assistants and to a lesser extent post-docs and lecturers. The former represent two-thirds of the participants. Let us note that when it started in 2003 the training was only open to new PhDstudent teaching assistants, hence its name, FormA, which stands for Formation Assistant-e-s or (teaching) assistant training (the original meaning of the name is now mostly forgotten). In terms of backgrounds, half of the participants come from the faculties of Law, Psychology and Education or Social Sciences and one quarter from Science or Medicine.

The second workshop is called the Instructional Skills Workshop (ISW). The first version of this workshop was developed a bit more than 35 years ago in the province of British Columbia, Canada. At its inception, the goal of the workshop was to provide the instructors of the newly developed colleges and institutes in the province with basic instructional skills. Indeed, it had been recognised that many instructors in those institutions had excellent professional or technical skills but lacked teaching credentials. At the University of Geneva, this workshop is given in English. It was started to address the need of providing training in university teaching to the non-French speaking teaching staff. Indeed, until the start of the ISW, all workshops in university teaching were given in French. The $I S W$ is given over 3 or 3.5 days. It is either open to participants from all faculties and departments, or organised specifically for one department. The core of the workshop is the series of three 10-minute lessons given by each participant to their peers. After each lesson, the teacher receives written and oral feedback from their peers. The teacher also receives the video of their lesson. In the feedback sessions, the role of the facilitator is to help the teacher self-evaluate their lesson and then to structure the oral feedback of the other participants so as to make it as rich as possible. The facilitator's role is also to create a safe space so that the feedback is respectful and non-threatening. The facilitator only gives indirect feedback through the questions he or she asks during the feedback session. The other key component of the workshop is the "theme sessions". These are theory 
sessions during which important concepts in university teaching are presented and addressed. They are all conducted in an active learning format and use as much as possible the principle of isomorphism. The participants can typically choose the topic of the last one or two sessions (usually from a list of proposed topics).

In terms of audience, the workshop is mainly followed by $\mathrm{PhD}$-student teaching assistants and post-docs. The former represent half of the participants. Lecturers and senior lecturers also constitute a part of the people following the workshop. Probably because it is conducted in English, two-thirds of the participants come from the Faculties of Science or Medicine.

In terms of content, the two workshops are close. In both we introduce the concepts of learning objectives, constructive alignment (Biggs and Tang 2011) and formative assessment. In both we also talk about Bloom's taxonomy (Anderson 2001), rubrics and ask participants to elaborate lesson plans. As FormA is longer and no micro-teaching is performed, more time can be devoted to these topics. The $I S W$ has a bigger practical part with the participants teaching three times; this gives the participants the opportunity to integrate the feedback received and make changes. The secure environment that the workshop provides is also an opportunity to experiment with new activities or forms of teaching. (Peer-)feedback thus plays a very important role in the $I S W$.

For this article, we decided to take these two workshops into consideration because they both constitute an overview of the basics of university teaching and run over several days. They thus constitute a material that is rich enough to make interesting analyses. We also wanted to take advantage of having two relatively equivalent, yet different, training programmes running in the same institution. Indeed, by being able to compare these two workshops, as opposed to "only" analyse one workshop, we are able to observe features and elements that would otherwise go unnoticed.

\section{METHOD}

In order to analyse these two workshops with an ethics of care perspective, we use the political ethics of care developed by Tronto (Tronto 1993, 2013) as an evaluative framework. Indeed, the usefulness of this framework for evaluating faculty development practices has been shown by Bozalek et al. (2014). More precisely, we use the five moral elements of care: attentiveness, responsibility, competence, responsiveness and trust. The first four were identified by Tronto and Fisher (Tronto 1993) and the last one - trust - by Sevenhuijsen (1998) and then acknowledged by Tronto (2013).

Our analysis and comparison of the workshops are based on two elements. First, we conducted semi-directed interviews with former participants; three having taken part in FormA 
and 4 in the $I S W$. The interviews took place between April and May 2016. They were conducted in person and followed a pre-established interview plan. To avoid, or at least minimise, any influence on the interviewees, the interviewer was not the person who had given the workshop. In other words, FormA's facilitator conducted the interviews with the participants of the ISW and vice-versa. The interviews were recorded and then transcribed. The choice of the participants invited to do an interview was based on their date of participation in the workshop (at most 1 year before the interview) and their availability.

In addition to the interviews, we have included the structures and contents of both workshops in our analysis. Namely, we have used the schedules and material provided to the participants of both workshops.

\section{DEFINITION OF CARE AND ITS FIVE ELEMENTS}

The definition of care we use is the one identified by Tronto and Fisher (Tronto 1993):

"... a species activity that includes everything we do to maintain, continue, and repair our 'world' so that we can live in it as well as possible. That world includes our bodies, our selves, and our environment, all of which we seek to interweave in a complex, life-sustaining web."

While being criticised as overly broad by some (e.g. Held 2006), the advantage of this definition is that it takes an integrated view of care that is not anchored in a specific context. Moreover, it goes beyond the family and domestic spheres. This holistic approach of care is particularly interesting for the context of faculty development; indeed, faculty development is an activity that involves many interconnected practices and goes beyond the direct relationship between faculty developers and faculty members. In addition, Tronto underlines that an "ethics of care is a practice, rather than a set of rules or principles" (Tronto 1993) which corresponds to our perspective of looking at concrete practices rather than general rules.

We now look individually at the five elements of care: attentiveness, responsibility, competence, responsiveness and trust.

\section{Attentiveness - caring about}

The first moral dimension of caring is to recognise the need of the other and to acknowledge that it should be met; failing to do so would be considered a "form of moral evil" (Tronto 1993). In order to do so, one should be able to take the position of the other. This implies that the need must be assessed at the individual level and not solely at a general level. Concerning faculty development workshops, this means that each time a workshop is given an assessment of the needs of the participants should be carried out before and/or during the workshop. 
Understanding the needs of a person means to understand them as humans and thus to know about their context and experiences.

In both workshops we ask the participants what their expectations for the workshop are. We also inquire about the questions they have about university teaching. This is in general done by email before the workshop. This is of course a rather basic way of assessing the needs. This is moreover not always very "efficient" as we regularly get vague answers such as "I want to know more about university teaching".

In the $I S W$, we take time at the beginning of each day to set up goals. Each participant sets up their own goals for the day (or for the workshop) and shares them with everyone else. This is a way for the facilitator to assess what the needs of the participants are.

The other main way of knowing about the participants' needs is through dialogue. In both workshops we try to create an atmosphere of dialogue that is both open and non-judgemental. When asked about the highlights of the workshop, one interviewee answers:

“... the big space created for exchanging [about teaching]. [...] This is new for me, I am not used to that. Within the university it is not like that at all. As soon as one says 'teaching', the conversation shifts to something else .... Here, not at all, on the contrary, we were willing to talk about [university teaching]." (Participant 2 of FormA, FormA2)

Concerning this aspect of getting to know the participants, one should mention here two features of the $I S W$ that may at first sight seem anecdotic but actually support attentiveness (as well as trust). The first one is that participants are encouraged to stay together with the facilitator for the coffee and lunch breaks. To do so, coffee and cookies are available in the room where the workshop takes place (other institutions also offer lunches to make sure participants don't "go away" during the lunch break). While probably not "spectacular", this simple measure enables the facilitator to get to know who the participants are as people, to know about their specific contexts, their life histories, experiences and frame of references. Indeed, understanding the needs of an individual requires more than only assessing the needs for the task at hand (Young 1997; Bozalek et al. 2014). This is noted by one of the interviewee who says that it "creates a warm atmosphere" and "certainly has a positive impact" (ISW1). Another interviewee remarks that "it was great! [...] It certainly [helps create a team spirit]" (ISW2).

Another feature of the $I S W$ that promotes attentiveness to the needs of the participants is to have a "parking lot" and time specifically dedicated to discuss the items on it. Concretely, it is a flip chart sheet with an empty parking lot drawn on it. At any time participants can write a question, concern or topic they would like to talk about and "park" it in one of the spots. The item is then addressed later during the day. This way participants can bring up topics or 
questions at any time, even when it is not the topic being discussed at that moment. This enables the facilitator to be aware of the questions the participants have about teaching in general. This also prevents questions from being brought up and then never addressed. Finally, by having time periods specifically devoted to questions and topics brought up by the participants, it gives the latter some level of control over the topics addressed in the workshop.

\section{Responsibility - caring for}

The second aspect of care is to take responsibility for an identified need. Responsibility goes beyond obligation; indeed, one can feel responsible for something or someone and take action while not having any obligation to do so. By going beyond obligation and formal duties, responsibility focuses on what is concretely being done or not done. This means that by taking responsibility one needs to determine one what should do for the other (Tronto 1993).

In the context of providing faculty development in a higher education institution, this notion of responsibility entails making sure that people interested in following our workshops can actually do so. At first element to mention here is that the creation of an English-speaking training programme at the University of Geneva completely follows this perspective of making sure that needs are met. Indeed, taking a different stance, one could argue that as the University's official language is French and the University is located in a French-speaking area, faculty development must be conducted in French. While this argument, which is based on principles, is defendable, from an ethics of care perspective it is not. Indeed, not providing support to non-French speaking teaching staff while being aware of the needs would be rejecting responsibility. This example illustrates well the difference between responsibility and obligation. Indeed, nothing "forces" the Teaching centre to offer workshops in English (since the University is officially French-speaking) but as Tronto notes, responsibility goes beyond formal rules and duties (Tronto 1993). It is thus out of responsibility that such training is now offered in English. Anticipating the next section on competence and its implications in terms of resources, let us note that offering a complete workshop in English implies having someone who masters English well enough to conduct such a workshop in that language. Not coincidentally, the $I S W$ started when a new staff member who had studied in English-speaking countries arrived at the Teaching and Learning Support Centre.

Another aspect of making sure that people interested in following a training programme in university teaching can do so is related to status. Indeed, as noted above, the majority of our participants are either $\mathrm{PhD}$ students or post-docs. As one knows, these are low-level (and thus potentially vulnerable) positions in the academic hierarchy. The difficulty that can show up is that some supervisors don't want their $\mathrm{PhD}$ student or post-doc attend a training programme on 
university teaching. Indeed, many professors view this as a time away from doing research and therefore a waste of time. This is something assistants are well aware of and it prevents some from registering and taking part in the workshops. This situation is reflected in comments such as

"Normally our bosses don't want us to attend this kind of training programmes on university teaching [...] just because they don't want us [the PhD students and post-docs] to lose time on the experiments. [...] This is not something our bosses will encourage." (ISW1)

Even someone with a senior (but non-faculty) position, mentions thinking about making sure that the timing for taking the workshop was good and that therefore the professor in charge of the chair they work in wouldn't be opposed to their participation in the workshop:

"I knew it wouldn't create a resistance from the professor I work with because it has been already seven years that I work with him. We know each other very well. He knows I enjoy teaching very much." (FormA2)

As faculty developers working in the university's Teaching and Learning Support Centre, we of course don't have the authority to "force" professors to allow their assistants to attend our workshops. This leaves us with the question: what can we do about it? Here is the example of two actions that have been used to address this problematic.

For several years, participants in FomA were requested to write a "letter of motivation" and have it signed by their hierarchical supervisor (i.e. in most cases by their thesis supervisor). One goal of this letter was to make sure that once the participant had signed up and got the approval of their supervisor, the latter would not be able to ask the participant to attend a meeting or give a deadline just during the workshop (another objective was to assess the participants' needs before the workshop). In that sense it was thought to "protect" the participants. It didn't, of course, prevent supervisors from simply saying no. Nor did it prevent people from not registering because they anticipated their supervisor would refuse to sign the letter. For this last reason, this measure has now been abandoned.

When the $I S W$ started at the University of Geneva, it was scheduled as a three-day block. This made the workshop quite intense and helped create a nice team spirit. Nevertheless, through discussions with the participants of the first occurrences of the workshop, it emerged that this schedule made their absence from the lab or office quite visible. Colleagues or supervisors would ask them where they had been for "so many days". People working in labs also expressed the difficulty it can represent to conduct experiments and be away from the lab for three days in a row (plus two if we add the week-end). The decision was thus taken to try a 
format of three and half days given over four weeks (i.e. one day per week for four weeks). According to informal feedback from the participants this has indeed made it easier for them to attend the workshop, simply by changing the perception of their colleagues about the length of their absence. This change of schedule shows how a small change can have a big impact on the participants (namely, the fact that they will be able to follow the training or not). Moreover, it exemplifies the need for the care giver to be attentive to people's actual lives and situations in order to meet their needs (Bozalek et al. 2014). In other words, one needs to consider people as a whole rather than focusing on one single aspect.

\section{Competence - care giving}

The third moral component of care is competence. In an ethics of care framework, competence means being sure that the care work is done and done well. This entails that the needs for care are being met. This also implies that problems are not only being "taken care of" on a superficial level without being actually addressed (Tronto 1993).

In the context of training programmes in university teaching, competence of course means having an expertise on university teaching so as to provide information that is both valid and relevant for the participants. Nevertheless, let us underline that this is only one aspect of competence (albeit an important one). One also needs to make sure that the needs of the participants are being met, which goes further than providing information. This aspect of competence and meeting the needs emerged in our interviews in several ways. One element that comes out clearly is the need to have a space to talk and exchange about teaching. One interviewee notes that:

“... university teaching, it is very solitary and it is a big problem because I like exchanging [and because] I think it is really an area where exchanging is an enriching experience." (FormA2).

That participant then explains that taking part in the workshop was "a way to satisfy this daily need" and that this prospect was a strong motivator to sign up for the workshop. Similarly, another interviewee notes "the lack of interest for [university teaching] in my department" (FormA1). Later that person remarks that the workshop's atmosphere was "convivial", it was not "super formal [...] which encourages people to talk to everyone else". As workshop facilitators, competence means here that we need create the conditions for this dialogue to happen and this isolation to be overcome. This echoes the words of Engelmann about the responsibility of university teachers "to take steps to overcome the relative isolation that has been the hallmark of college and university teaching" (Engelmann 2009). To address this need of dialogue, in both workshops we try to create favourable conditions by organising many group 
activities in which the participants have the opportunity to share their experiences. This is also why in the $I S W$ we organise breaks in a way that encourages participants to stay together and exchange. In the $I S W$, we moreover schedule time slots that are specifically dedicated to the participants' questions and concerns. This is a way to make sure that they can exchange about what is important for them and that their need for dialogue is met. This is a need that could easily be only "superficially taken care of" (Tronto 1993), for instance by saying that the participants have plenty of opportunities to exchange outside of the workshop or that we do answer questions when there is in fact no time really dedicated to it.

Another aspect that comes out in our interviews is the importance of getting feedback from peers. This probably underlines the need of being acknowledged and the desire to improve. Indeed, most interviewees mention getting feedback as a highlight of the workshops. Interestingly, this element came both from participants of the ISW and Form $A$ even though this aspect isn't as much emphasised in the latter. For example, one interviewee notes that "feedback sessions [were] very important" (ISW1). Later in the interview that person notes that teaching three times in order

"to see the progress made, it was really important. [...] I know what my weaknesses and strengths are and now I can adapt my courses on that base. It is something I think I'll never forget."

These words echo the remark of another participant:

"[The most striking part] was to see the progression between the first presentation on the first morning, with the feedback of the others, and the last day again the presentations with new comments once we had done all the changes." (FormA3).

It is furthermore interesting to note that when prompted on what they retain from the workshop, all participants spontaneously talk about the general atmosphere, the space created for exchanging, the fact of receiving feedback but not about the content itself (such as, for example, active learning or constructive alignment). This probably denotes the need of being in contact with peers who are also interested in teaching. This also means that "simply" delivering content about university teaching cannot be considered as caring competently about the participants but rather as failing to provide good care (Tronto 1993).

One last important aspect of competence, or making sure that the needs of the participants are met, is to ensure that they will be able to use their newly acquired skills. In other words, it is important to support the transfer of the newly acquired knowledge and skills to the participants' contexts. In FormA, it is the role of the validation work. Indeed, during that phase participants receive feedback and support from a faculty developer to help them bridge the gap 
between theory and practice. The other advantage is that the participants are in a "real" context with genuine constraints (such as class size or time devoted to a given topic). Participants can thus develop an "operational final product" (FormA2). In the ISW, we don't offer such a possibility. The main reason is the lack of resources to do this follow up. This points out the resource implications of providing care competently.

\section{Responsiveness - care receiving}

The fourth element of caring is responsiveness, in other words, to pay attention to how the care receivers respond to the care is provided. This implies that as a care giver one cannot a priori assume that the care well received and that the receivers' needs are satisfied. One needs to enquire into this question of the reception of the care. Moreover, because of the difference in status that often exists between the care giver and the care receiver, one should always "remain alert to the possibilities for abuse" (Tronto 1993).

In the case of faculty development training programmes, the care givers are the facilitators whereas the participants are the care receivers. As faculty developers, this implies that we should enquire into how and to what extent our training programmes do answer the needs of the participants.

In order to know how the care we provide to our workshop participants is received and appreciated, we assess this aspect in several ways. First, we routinely run end-of-workshop surveys. These are sent afterwards by email to the participants and the answers are anonymous. While this instrument gives us interesting information about the opinions of the participants, it also has limitations. The first obvious limitation is that we only get this feedback after the workshop is done. It can therefore only be used to make changes for future workshops. But as these workshops will be attended by new participants who have unique (and probably slightly different) needs, this practice in itself cannot be considered as being responsive to the care provided. In addition, let us note that in terms of responsibility it then really relies on the facilitator(s) to analyse the surveys and implement the proposed changes. While simple in theory, it is not always easy practice due to time constraints and amount of time one can devote on workshop preparation and follow up. Nevertheless, failing to do so would amount to only superficially "take care of" the participants' needs (Tronto 1993). Another aspect that is a limitation of this tool is the questions asked in the survey. Indeed, the dominant discourse of the time emphasising values such as effectiveness, measurability or quality, it is easy to leave out aspects related to care ${ }^{1}$ (Olssen and Peters 2005; Land 2004). Our surveys are probably typical in the sense that they are clearly influenced by the notions of measurability and attainment of objectives and only indirectly address the notions of needs and care. For example, 
questions such as "The way the different thematics were treated was clear" or "The workshop helped me develop skills in using learning objectives" focus on the delivery and acquisition of a skill. Other questions address more the aspect of the participants' needs, for example: "The material covered is relevant to my teaching activities" or "The objectives are relevant with regard to my training needs". Nevertheless, we don't address directly the question of what the needs of the participants are, how they were satisfied or not or how it was done. The influence of measurability is also seen in the fact that most questions are rated on a 4-point scale and only a few ones are open-ended. On the surveys, we thus see that changes could be done to take more into account the notion of care.

To avoid this problem of the timing of the feedback, in the $I S W$ we also collect formative feedback from the participants at the end of each day. The participants answer in writing to prompts such as "What worked for me today", "Suggestions of tomorrow" or "A question without answer". In this way, we can adapt from one day to the next and (hopefully) provide better care to the participants. A summary of the feedback received is always done at the beginning of the following day. This moment is an opportunity for the facilitator(s) to acknowledge the feedback received and show to the participants that their opinion is taken into account. It is also an opportunity for the facilitator(s) to share with the participants what, in their opinion, worked well or not so well. To use Engelmann's words, it is a strategy "that democratizes education by sharing authority and responsibility for learning with the students, rather than reserving it to the teacher" (Engelmann 2009). With this same idea of sharing authority, $I S W$ 's participants can always choose the last one or two theme session(s) by either picking a topic from a proposed list or by suggesting one. Moreover, there is every day a time slots devoted specifically to the participants' questions or concerns.

In FormA, an assessment discussion is organised at the end of the workshop. This session is aimed at collecting the participants' first impressions and to give them the possibility to explain them orally. It is also a moment where the facilitators can give their own impressions how the workshop went for them and engage in a discussion with the participants. In some sense, it is also a way to level the difference in status between the facilitators and the participants.

\section{Trust - caring with}

The last element of care is trust. It was first identified by Sevenhuijsen (1998), along with plurality, communication and respect, and then acknowledged by Tronto (Tronto 2013). As Sevenhuijsen puts it, trust is like the "oil" that makes the other components of care work together (2003). She also notes that a "situation of hierarchy or asymmetry in power relations" 
makes it more difficult to establish trust. This is typically the case in a training programme where the facilitators have a role of authority over the participants.

In the $I S W$, trust is a central element. Indeed, as peer-feedback is very important in the workshop, it is necessary that the participants trust each other. Moreover, as we encourage them to try new teaching activities and methods, we don't want the fear of failure or of losing control to prevent them from trying something new. We also want our participants to be able to express themselves openly about teaching and about their university experience. This is even more important when the workshop is organised for a specific department, where people tend to know each other more.

To build trust we emphasise the principle of confidentiality. Concretely this means that we ask participant to make sure that when they talk about a specific thing another participant has said or done, one cannot recognise who that person is. The goal is to build trust and make sure that people feel free to express themselves. As one participant notes: "it was reassuring to know that everything stays between us, in our space" (ISW1).

Another element (mentioned earlier) that contributes to building trust between the participants and the facilitators and among the participants themselves is that coffee and lunch breaks are spent together. This way, everyone has the possibility to get to know each other better as a person and not only as a teaching assistant or lecturer. In the same spirit, an emphasis is given to ice breaker activities.

Another aspect worth mentioning is the spatial organisation of the room. In order to reduce the difference in hierarchy between the facilitator and participants, tables are arranged so as to have one big table around which everyone sits. There is therefore no divide between the teacher and the students (as opposed to what often happens in traditional classrooms). In addition to promoting interactions, it implicitly sends the message that everyone's contribution is welcome and treated as equal (Gair and Mullins 2001; Margolis 2001) and thus shares authority with the students rather than reserving it to the teacher (Engelmann 2009). In the same vein, participants are put in "position of power". Indeed, when they teach their lesson, they are in charge and have the authority. They can reorganise the spatial organisation of the room, have the other participants do some exercises, etc. By putting the participants in such a position of authority, we try to level down this asymmetry in power relations.

In FormA there is not such an emphasis on trust. One element one should nevertheless mention is the common use of first names and the informal form of "you" (indeed, similarly to languages such as Spanish or German, there are in French two forms for "you", a formal one and an informal one). While this may be common between colleagues, it is in general uncommon between people who do not know each other. Moreover, it is definitely uncommon 
in a university setting between teachers and students. In the training programme, it is therefore a way to reduce the gap that could exists between the facilitators and the participants. On this aspect, one interviewee notes: "it is very good that it is not very formal [and that the facilitators don't say] that what we did is right or wrong but rather that everything is discussed and nuanced" (FormA1).

\section{SMALL THINGS AS A BASIS FOR DEEPER CHANGES?}

So far, we have analysed our practice as faculty developers using the five elements of care identified by Tronto. This framework has enabled us to identify small things in our practice that actually have big impact in terms of the actual care provided to the workshop participants. For example: giving some level of choice to the participants over the topics addressed in the workshop, adapting the schedule to make sure people interested in the workshops can attend, scheduling time slots specifically dedicated to answer questions and concerns brought up by the participants, requesting regular anonymous feedback from the participants about the workshop and making immediate changes accordingly, creating a climate of trust and dialogue by emphasising the principle of confidentiality, spatially organising the room in a way that put the participants at the same level as the facilitators. In the introduction we mentioned that this perspective gives an interesting counterbalance to values such as efficiency, expertise and performance. Yet, one could go further and argue that these small things may actually operate at a deeper level. Indeed, if one considers the ethics of care not only as an evaluative framework but also as a basis for reconceptualising faculty development, these small changes could spiral into much bigger ones. In that sense, an ethics of care approach can (some would say should) be used not only to counterbalance "business as usual" but to actually rethink and reconceptualise faculty development as a whole.

\section{CONCLUSION}

In this article, we have shown how the ethics of care framework can be used as an evaluative framework to assess faculty development training programmes in higher education. This holistic approach centred on the notion of people's needs appears to be particularly relevant and useful for both assessing and elaborating such activities. Indeed, university teacher training programmes (and faculty development in general) being composed of many interconnected practices that each has its own different facets; it is only by taking such a global approach that one can appropriately depict and evaluate these programmes. Moreover, by focusing on the notion of care, this framework puts a stress on the satisfaction of people's needs. This leads to paying attention to notions such as attentiveness to the needs, relationality and responsiveness 
to the care provided. It therefore not only offers a suitable counterbalance to the morecommonly-used values of performance, expertise or measurability but also provides a potential basis for rethinking and reconceptualising such activities.

Our analysis and comparison of the two workshops under consideration for this case study - Form $A$ and the $I S W$ - shows that the ethics of care approach has enabled us to identify several important practices that would otherwise have gone unnoticed. For both workshops, we have for instance pointed out the importance for the participants of having a safe space for exchanging about university teaching. The usefulness of measures such as stressing the principle of confidentiality, having people to get to know each other as persons and not only as teaching assistants or lecturers, or adapting the schedule then becomes clear. We have also seen how gathering feedback from the participants at the end of each day or giving them the choice of certain topics can help the facilitators identify and satisfy the actual needs of the participants. Another element that came out is the different place that takes expertise. Indeed, while still important, expertise on the subject matters becomes "only" one component amongst several other important ones. We clearly see that expertise alone is not enough to make sure that people's needs are satisfied. Finally, the importance of the types of questions asked in an evaluation survey became obvious. Indeed, as the questions asked implicitly convey certain values, it is important, when designing such surveys, to identify which values one is really inquiring about.

In this article, we have focused on showing the benefits of taking an ethics of care approach on faculty development. We also wanted to show how this can lead to making small changes with potential big impacts for the participants. One line of inquiry that goes beyond the scope of this article and that would be worth investigating in the future would be to focus on the faculty developers. More precisely, it would be interesting to focus on the needs of the facilitators of such workshops and how they can be satisfied.

To sum up, we hope that this article will be used by others as a stepping stone to develop a more caring approach on faculty development and to lead studies that would complement the findings presented here.

\section{ACKNOWLEDGEMENT}

We would like to thank the two anonymous reviewers for their interesting suggestions and ideas on how to improve this article.

\section{NOTE}

1. In Europe for example, this can be seen with the Bologna process and its emphasis on 
measurability and quality assurance. On a more global scale, the various university rankings denote a similar trend.

\section{REFERENCES}

Anderson, Lorin W. 2001. A taxonomy for learning, teaching, and assessing: A revision of Bloom's Taxonomy of educational objectives. Complete ed. New York: Longman.

Biggs, J. B. and Catherine Tang. 2011. Teaching for quality learning at university: What the student does. 4th Edition. Philadelphia, Pa.; Maidenhead, Berkshire, England; New York: McGrawHill/Society for Research into Higher Education: Open University Press.

Bozalek, Vivienne Grace, Wendy McMillan, Delia E. Marshall, Melvyn November, Andre Daniels and Toni Sylvester. 2014. Analysing the professional development of teaching and learning from a political ethics of care perspective. Teaching in Higher Education 19(5): 447-458. doi:10.1080/13562517.2014.880681.

Engelmann, Donna. 2009. Another look at a feminist ethics of teaching. Atlantis: Critical Studies in Gender, Culture \& Social Justice 33(2): 62-71.

Gair, Marina and Guy Mullins. 2001. "Hiding in plain sight." In The hidden curriculum in higher education, ed. Eric Margolis, 21-42. New York, NY: Routledge.

Held, Virginia. 2006. The ethics of care. Oxford Scholarship Online Monographs.

Land, Ray. 2004. Educational development: Discourse, identity and practice. Open University Press. http://strathprints.strath.ac.uk/8501/

Margolis, Eric. (Ed.). 2001. The hidden curriculum in higher education. New York, NY: Routledge.

Olssen, Mark and Michael A. Peters. 2005. Neoliberalism, higher education and the knowledge economy: From the free market to knowledge capitalism. Journal of Education Policy 20(3): 313345. doi:10.1080/02680930500108718.

Sevenhuijsen, Selma. 1998. Citizenship and the ethics of care: Feminist considerations on justice, morality and politics. London: Routledge.

Sevenhuijsen, Selma. 2003. The place of care: The relevance of the feminist ethic of care for social policy. Feminist Theory 4(2): 179-97. doi:10.1177/14647001030042006.

Tronto, Joan C. 1993. Moral boundaries: A political argument for an ethic of care. New York: Routledge.

Young, I. M. 1997. Asymmetrical reciprocity: On moral respect, wonder, and enlarged thought. CONSTELLATIONS - OXFORD - 3(3): 340-63. 